Gut, 1972, 13, 867-870

\title{
Disappointment with triethers as markers for measuring triglyceride absorption in man
}

\author{
D. R. SAUNDERS AND T. K. O'BRIEN with the technical assistance of KENT SMITH \\ From the Division of Gastroenterology, Department of Medicine, University of Washington, Seattle, \\ Washington
}

SUMMARY Glycerol triethers were tried as non-absorbable, oil-phase markers for indirectly measuring triglyceride absorption in the human proximal jejunum. Tritium labelled 1-hexadecyl-2, 3-didodecyl glycerol, or 1,2,3-trioleyl glycerol, or 1,2,3-tridecyl glycerol was dissolved in linseed oil and egg yolk lipids; an aqueous emulsion of the lipid mixture was infused into the stomach. Unexpectedly, postprandial jejunal contents contained proportionately less triether than triglyceride compared with the test meals. These triethers were found to separate from an aqueous phase at a faster rate than the triglyceride. This dissociation occurred in the stomach and thwarted quantification of triglyceride absorption by this test system.

Complete recovery of luminal contents at any site in the normal human small intestine is not possible. An indirect method, therefore, has been used to measure how much fed fat has been absorbed proximal to a point where small intestinal contents are being aspirated. A homogeneous test meal is made to contain a known ratio of an unabsorbable marker to an absorbable fat. An increase in the ratio of marker to fat in the aspirated intestinal contents represents absorption of fat proximal to the point of sampling.

The validity of this indirect method depends upon the inseparability of marker and fat except when separation is caused by the absorption of fat. Polyethylene glycol (PEG) was used as an unabsorbable marker for experiments on fat absorption in the human small intestine (Borgström, Dahlquist, Lundh, and Sjövall, 1957). Wiggins and Dawson (1961) found that test meals dissociated into two phases in the human stomach: an oily phase rich in fat, and an aqueous phase rich in marker. The aqueous phase tended to leave the stomach more rapidly. Thus, PEG fat ratios in antral contents could be changing continuously. Subsequent calculations of the extent of fat absorption in the small intestine may be inaccurate, although correction factors have been offered (Borgström, Dahlquist, and Lundh, 1962).

To overcome this difficulty, a tritiated triether (1-hexadecyl-2, 3-didodecyl glycerol) has been proposed as a triglyceride marker (Morgan and Hofmann, 1970a). Its ether linkages are resistant to

Received for publication 19 September 1972. digestive and bacterial enzymes; virtually all of an oral dose of triether was excreted unchanged in the stool. Furthermore, the triether moved completely into the oily phase when it was partitioned between an oil phase of triolein and an aqueous micellar phase (Morgan and Hofmann, 1970a). Its use was validated in rats with cholestyramine-induced steatorrhoea (Morgan and Hofmann, 1970b), and there are preliminary reports in which this triether was utilized for quantifying fat absorption in man (Weiss and Holt, 1970, 1972).

In our system for studying the digestion and absorption of triglyceride in the human proximal small intestine, an aqueous emulsion of lipids is infused into the stomach. Fat digestion is assessed by chemical analysis of duodenojejunal contents (Porter and Saunders, 1971); fat absorption is evaluated by electron microscopy of jejunal mucosal biopsies (Porter, Saunders, Tytgat, Brunser, and Rubin, 1971) We were unsuccessful in our attempt to quantify triglyceride absorption by incorporating a triether marker into our test meal. The purpose of this communication is to emphasize a potential artifact if glycerol triethers are used in indirect tests of triglyceride absorption in man.

\section{Materials and Methods}

1-Decanol (Hormel Institute, Austin, Minnesota), 1-dodecanol (Lachat Chemicals, Chicago, Illinois), 1-hexadecanol (J. T. Baker), 1-octadecanol (Hormel), and $\left[2{ }^{3} \mathrm{H}\right]$ glycerol (New England Nuclear Corporation) were used without further purification. 
Glycerol ethers were synthesized according to the methods of Baumann and Mangold (1966) except that we used $\left[2-{ }^{3} \mathrm{H}\right]$ glycerol as a starting material. Final products were purified on columns of silicic acid as suggested by Morgan and Hofmann (1970a). All synthesized triethers gave a single spot when a chromatoplate of silica gel $\mathbf{H}$ was spotted with $200 \mu \mathrm{g}$ of a triether, was developed in hexane-diethyl ether, 18:1, and was sprayed with sulphuric acid and heated. Infrared analyses (Beckman, Model IR4) showed a band for ether $-\mathrm{C}-\mathrm{O}-\mathrm{C}$ at $1120 \mathrm{~cm}^{-1}$, bands for $-\mathrm{CH}_{2}$ at $2940,2850,1460,1365 \mathrm{~cm}^{-1}$, but no band for trans $\mathrm{C}-\mathrm{H}$ at $965 \mathrm{~cm}^{-1}$, nor for ester $-\mathrm{CO}-\mathrm{O}-\mathrm{C}$ at $1720 \mathrm{~cm}^{-1}$. Radioactive purity was assessed by thin-layer chromatography and liquid scintillation spectrometry: chromatoplates were developed in hexane-diethyl ether, 18:1, and were stained with iodine vapour; the triether area was scraped into a counting vial and was mixed successively with $1 \mathrm{ml}$ of $10 \%$ acetic acid in ethanol and with $10 \mathrm{ml}$ of toluene-phosphor. The radioactive purity of 1-hexadecyl 2, 3-didocecyl-[ $\left.{ }^{3} \mathrm{H}\right]$-glycerol was $97 \cdot 1 \%$; of 1,2,3-trioleyl-[ $\left.{ }^{3} \mathrm{H}\right]$-glycerol, $93.0 \%$; and of 1,2,3-tridecyl- $\left[{ }^{3} \mathrm{H}\right]$-glycerol, $100 \%$. The chemical purity of two triethers was assessed by elemental analysis (Huffman Laboratories, Wheatridge, Colorado). That found for trioleyl glycerol was as follows: $\mathrm{C}, 81.48 \% ; \mathrm{H}, 13.58 \% ; \mathrm{O}, 5.06 \%$. $\mathrm{C}_{57} \mathrm{H}_{110} \mathrm{O}_{2}$ requires $\mathrm{C}, 81 \cdot 16 \% ; \mathrm{H} 13 \cdot 14 \%$; $\mathrm{O}$, $5.69 \%$. That found for tridecyl glycerol was: C, $77.06 \% ; \quad \mathrm{H}, 13.23 \% ; \quad \mathrm{O}, \quad 9.84 \% . \quad \mathrm{C}_{33} \mathrm{H}_{68} \mathrm{O}_{3}$ requires $\mathrm{C}, 77 \cdot 27 \% ; \mathrm{H}, 13.36 \% ; \mathrm{O}, 9.35 \%$.

The test meal consisted of the lipids from two egg yolks and $10 \mathrm{ml}$ of linseed oil (Hain Pure Food Co., Los Angeles, Calif.) in which was dissolved $80 \mathrm{mg}$ of 1-hexadecyl-2, 3-didodecyl glycerol, or $32 \mathrm{mg}$ of 1,2,3-trioleyl glycerol, or $22 \mathrm{mg}$ of 1,2,3-tridecyl glycerol; these lipids were blended for two minutes in an Osterizer with $400 \mathrm{ml}$ of Travamin $(5 \mathrm{~g}$ of casein hydrolysate and $5 \mathrm{~g}$ of dextrose per $100 \mathrm{ml}$, Travenol Laboratories, Deerfield, Illinois) adjusted $p \mathrm{H}$ 6.5. Linseed oil consists of triglycerides whose predominant fatty acid is linolenic acid. Thus, there are 28 moles of linolenic acid per 100 moles of fatty acid in the test meal. Because linolenic acid is readily absorbed (Fernandes, van de Kamer, and Weijers, 1962; Peterson, 1963), and because it occurs in only trace amounts in human bile (Nakayama, 1967) or in human small intestinal mucosa (Saunders, Ways, Parmentier, and Rubin, 1966), it serves as the label for absorbable triglyceride in the test meal.

Three series of experiments were performed. In the first series, we tested the ability of a triether marker to detect triglyceride absorption by the proximal small intestine. After positioning a sump tube (internal diameter, $3 \mathrm{~mm}$ ) at the duodenojejunal junction, the test meal was infused intragastrically over 15 minutes. Fifteen minutes later, intestinal contents were aspirated continuously over the following one half hour; ${ }^{3} \mathrm{H}$ and linolenic acid were quantified in duplicate assays of the thoroughly mixed intestinal contents.

In the second series of experiments, we tested whether triethers dissociated from the triglyceride in the test meal in the stomach. Under fluoroscopic control a sump tube (internal diameter $3 \mathrm{~mm}$ ) was placed in the antrum of a normal subject. Antral contents were obtained after the test meal was infused intragastrically via a feeding tube.

In the final experiments, we tested whether triethers separated from the triglyceride in the test meal in vitro. Homogenized test meals were placed in separatory flasks which were then maintained at $23^{\circ} \mathrm{C}$ or at $37^{\circ} \mathrm{C}$. At intervals, samples of the lower portion of the meal were taken by opening the stopcock of the flask.

Lipids were extracted into chloroform-methanol (Folch, Lees, and Sloane-Stanley, 1957). Methyl esters of fatty acids (Helander, 1970) were quantified by gas liquid chromatography using heptadecanoic acid as an internal standard. Tritium was measured in a Beckman liquid scintillation counter; $\left[{ }^{3} \mathrm{H}\right]$ toluene was used as an internal standard to correct for quenching.

\section{Results and Discussion}

All but one of the four human subjects had an anomalous decrease in tritium:linolenate ratios in their duodenojejunal contents (Table I). Because percentages of lipolysis (free fatty acids $\times 100 \div$ total fatty acids) were normal, and because free fatty acids are rapidly absorbed by the proximal small intestine (Borgström et al, 1957), the ratio of tritium to linolenic acid should have increased.

The possibility that the triether was dissociating in the stomach from the triglyceride in the test meal was proven in the second series of experiments (Table II). In the three subjects studied, tritium: linolenate ratios in antral contents declined progressively. In order to prove that this phenomenon was not due to gastric absorption of triether or to errors of sampling, we showed that triethers separated from triglycerides in test meals in vitro at room temperature and at $37^{\circ} \mathrm{C}$ (Table III).

We conclude that dissociation of triether from triglyceride begins shortly after the test meal has been blended and continues in the stomach. The dependent portion of the meal, poor in marker, would be the first to enter the duodenum. Even if separation of a meal's components could be delayed in vitro, it is likely that gastric pepsin would denature 


\begin{tabular}{lllll}
\hline Subject & Sample & {$\left[{ }^{3} \mathrm{H}\right]$ Triether $($ dpm $/ \mathrm{ml})$} & Linolenate $($ mumole/ml) & Ratio $($ dpm/mumole $)$ \\
\hline L.C. & Test meal & 6500 & 2200 & $2 \cdot 95$ \\
& intestinal contents & 1690 & 820 & $2 \cdot 09$ \\
J.M. & Test meal & 7700 & 3350 & $2 \cdot 30$ \\
& intestinal contents & 2750 & 1270 & $2 \cdot 16$ \\
J.O. & Test meal & 7300 & 3200 & $2 \cdot 28$ \\
& intestinal contents & 1970 & 1320 & $1 \cdot 49$ \\
B.N. & Test meal & 6840 & 3400 & $2 \cdot 01$ \\
& intestinal contents & 3120 & 1170 & $2 \cdot 67$ \\
\hline
\end{tabular}

Table I Marker-fat ratios of test meals and of duodenojejunal contents ${ }^{1}$

'Each subject was given a meal which contained $80 \mathrm{mg}$ of 1 -hexadecyl-2, 3-didodecyl-8 $\mathrm{H}$-glycerol. The test meals were blended for two minutes and then were infused over 15 minutes into the stomach. The blended test meal was maintained at $23^{\circ}$ for L.C. and J.M., and at $37^{\circ}$ for J.O. and B.N. Duodenojejunal contents were aspirated over 30 to 60 minutes after beginning the intragastric infusion. Values are the means of duplicate determinations. Only in B.N. was there an increase in the ratio of ${ }^{3} \mathrm{H}$ to fatty acid suggesting that glyceride fatty acid was absorbed; the decreases in the ratio in the other subjects are anomalous.

\begin{tabular}{|c|c|c|c|c|}
\hline Subject & Time of Sampling (min) & {$\left[{ }^{3} H\right]$ Triether $(d p m / m l)$} & Linolenate (mumole $/ \mathrm{ml}$ ) & Ratio (dpm/mumole) \\
\hline T.B. & $\begin{array}{r}0 \\
15 \\
30 \\
60\end{array}$ & $\begin{array}{l}7500 \\
6200 \\
2600 \\
3100\end{array}$ & $\begin{array}{l}2300 \\
2000 \\
1200 \\
1200\end{array}$ & $\begin{array}{l}3 \cdot 26 \\
3 \cdot 10 \\
2 \cdot 16 \\
2 \cdot 58\end{array}$ \\
\hline J.D. & $\begin{array}{r}0 \\
15 \\
30 \\
60\end{array}$ & $\begin{array}{l}7300 \\
5900 \\
4300 \\
2500\end{array}$ & $\begin{array}{l}2200 \\
2300 \\
1900 \\
1400\end{array}$ & $\begin{array}{l}3 \cdot 32 \\
2 \cdot 56 \\
2 \cdot 26 \\
1 \cdot 79\end{array}$ \\
\hline B.N. & $\begin{array}{r}0 \\
45\end{array}$ & $\begin{array}{r}10290 \pm 230 \\
6210 \pm 120\end{array}$ & $\begin{array}{l}3180 \pm 70 \\
2060 \pm 60\end{array}$ & $\begin{array}{l}3.24 \pm 0.11 \quad P<0.05 \\
3.02 \pm 0.11\end{array}$ \\
\hline
\end{tabular}

Table II Marker-fat ratios of antral contents ${ }^{1}$

'Subjects were given test meals which contained 1-hexadecyl 2, 3-didodecyl [ $\left.{ }^{3} \mathrm{H}\right]$ glycerol. The meals were blended for two minutes in an Osterizer; the blended meals were maintained at $23^{\circ} \mathrm{C}$ for T.B. and J.D. and at $37^{\circ} \mathrm{C}$ for B.N. and were infused into the stomach over 10 minutes. In B.N. the values are means $\pm S D(N=4)$.

\begin{tabular}{|c|c|c|c|c|c|c|}
\hline Triether Marker & Temperature $\left({ }^{\circ} \mathrm{C}\right)$ & $\begin{array}{l}\text { Time of Sampling } \\
\text { (min) }\end{array}$ & $\begin{array}{l}{ }^{\left[{ }^{3} \mathrm{H}\right] \text { Triether }} \\
(\mathrm{dpm} / \mathrm{ml})\end{array}$ & $\begin{array}{l}\text { Linolenate } \\
(\text { mumole } / m I)\end{array}$ & \multicolumn{2}{|c|}{ Ratio $^{2}(\mathrm{dpm} / \mathrm{mumole})$} \\
\hline 1-Hexadecyl-2, 2-Didodecyl & 23 & $\begin{array}{r}0 \\
15 \\
30 \\
60\end{array}$ & $\begin{array}{l}7700 \\
1100 \\
1000 \\
1000\end{array}$ & $\begin{array}{r}2200 \\
400 \\
600 \\
600\end{array}$ & $\begin{array}{l}3.5 \\
2.8 \\
1.7 \\
1.7\end{array}$ & \\
\hline 1-Hexadecyl-2, 3-Didodecyl & 37 & $\begin{array}{r}0 \\
60\end{array}$ & $\begin{array}{r}12100 \\
4100\end{array}$ & $\begin{array}{r}2500 \\
900\end{array}$ & $\begin{array}{l}4.90 \pm 0.10 \\
4.56 \pm 0.15\end{array}$ & $P<0.02$ \\
\hline Trioleyl & 23 & $\begin{array}{r}0 \\
60\end{array}$ & $\begin{array}{r}4300 \\
380\end{array}$ & $\begin{array}{r}3300 \\
370\end{array}$ & $\begin{array}{l}1.27 \pm 0.01 \\
1.05 \pm 0.03\end{array}$ & $P<0.01$ \\
\hline Trioleyl & 37 & $\begin{array}{r}0 \\
60\end{array}$ & $\begin{array}{r}4420 \\
450\end{array}$ & $\begin{array}{r}3510 \\
470\end{array}$ & $\begin{array}{l}1.26 \pm 0.01 \\
0.96 \pm 0.05\end{array}$ & $P<0.01$ \\
\hline Tridecyl & 23 & $\begin{array}{r}0 \\
60\end{array}$ & $\begin{array}{r}17240 \\
1970\end{array}$ & $\begin{array}{r}3840 \\
470\end{array}$ & $\begin{array}{l}4.53 \pm 0.14 \\
4.24 \pm 0.08\end{array}$ & $P<0.02$ \\
\hline Tridecyl & 37 & $\begin{array}{r}0 \\
60\end{array}$ & $\begin{array}{r}17100 \\
2650\end{array}$ & $\begin{array}{r}3850 \\
610\end{array}$ & $\begin{array}{l}4.44 \pm 0.05 \\
4.31 \pm 0.08\end{array}$ & $P<0.05$ \\
\hline
\end{tabular}

Table III Marker-fat ratios of homogenized meals in vitro ${ }^{1}$

${ }^{1}$ Meals were blended for two minutes in an Osterizer and then were placed in separatory funnels at $23^{\circ} \mathrm{C}$ or at $37^{\circ} \mathrm{C}$. Samples were taken from the bottom of the column of fluid by opening the stopcock.

${ }^{2}$ The values in all but the first experiment are means $\pm S D(N=4)$.

added proteinaceous emulsifiers, and that acidic gastric contents might precipitate added ionic detergents.

Triethers will tend to separate from triglycerides in the small intestine. There, triglyceride digestion products, fatty acid and monoglyceride, will be transferred to the aqueous micellar phase (Hofmann and Borgström, 1964) from the oily phase which contains the triether. Interpretation of indirect measurements on the extent of triglyceride absorp- 
tion will be difficult, therefore, unless the oil-phase marker technique has been carefully validated.

Supported by research grant CA 04320 from the National Cancer Institute, National Institutes of Health and United States Public Health Service; the Clinical Research Center of the University of Washington (National Institutes of Health grant FR-37); gastroenterology training grant 5T1 A, 5099 (Dr O'Brien) and research cancer development award K4-AM-35, 150 (Dr Saunders) from the National Institutes of Health.

\section{References}

Baumann, W. J., and Mangold, H. K. (1966). Reactions of aliphatic methane-sulfonates. II. Synthesis of long-chain di- and trialkyl glyceryl ethers. J. org. Chem., 31, 498-500.

Borgström, B., Dahlquist, A., and Lundh, G. (1962). On the site of absorption of fat from the human small intestine. Gut, 3, 315317.

Borgström, B., Dahlquist, A., Lundh, G., and Sjövall, J. (1957). Studies of intestinal digestion and absorption in the human. $J$. cli. Invest., 36, $1521-1536$.

Fernandes, J., van de Kamer, J. H., and Weijers, H. A. (1962). Differences in absorption of the various fatty acids studied in children with steatorrhea. J. clin. Invest., 41, 488-494.

Folch, J., Lees, M., and Sloane-Stanley, G. H. (1957). A simple method for the isolation and purification of total lipids from animal tissues. J. biol. Chem., 226, 497-509.
Helander, H. F. (1970). Lipolysis and lipid absorption in the stomach of the suckling rat. Gastroenterology, 59, 22-35.

Hofmann, A. F., and Borgström, B. (1964). The intraluminal phase of fat digestion in man: The lipid content of the micellar and oil phases of intestinal content obtained during fat digestion and absorption. J. clin. Invest., 43, 247-257.

Morgan, R. G. H., and Hofmann, A. F. (1970a). Synthesis and metabolism of glycerol ' $\mathrm{H}$ triether, a nonabsorbable oil-phase marker for lipid absorption studies. J. Lipid Res., 11, 223-230.

Morgan, R. G. H., and Hofmann, A. F. (1970b). Use of 'H-labelled triether, a nonabsorbable oil-phase marker, to estimate fat absorption in rats with cholestyramine-induced steatorrhea. J. Lipid Res., 11, 231-240.

Nakayama, F. (1967). Quantitative microanalysis of bile. J. Lab. clin. Med., 69, 594-609.

Peterson, M. L. (1963). On the reesterification of fatty acids during absorption of fat: Studies in patients with chyluria. Gastroenterology, 44, 774-786.

Porter, H. P., and Saunders, D. R. (1971). Isolation of the aqueous phase of human intestinal contents during the digestion of a fatty meal. Gastroenterology, 60, 997-1007.

Porter, H. P., Saunders, D. R., Tytgat, G., Brunser, O., and Rubin, C. E. (1971). Fat absorption in bile fistula man. A morphological and biochemical study. Gastroenterology, 60, 1008-1019.

Saunders, D. R., Ways, P. O., Parmentier, C. M., and Rubin, C. E. (1966). Studies on the lipid composition of human small bowel mucosa. J. clin. Invest., 45, 1516-1525.

Weiss, J. B., and Holt, P. R. (1970). Steady state intestinal perfusion of a mixed meal in man. Clin. Res., 18, 683.

Weiss, J. B., and Holt, P. R. (1972). Factors related to fat absorption during constant intraduodenal perfusion of a lipid meal in man. Gastroenterology, 62, 827.

Wiggins, H. S., and Dawson, A. M. (1961). An evaluation of unabsorbable markers in the study of fat absorption. Gut, 2, 373-376. 